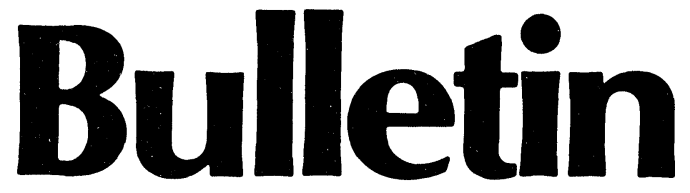

(New Series)

of the

\title{
American Mathematical Society
}

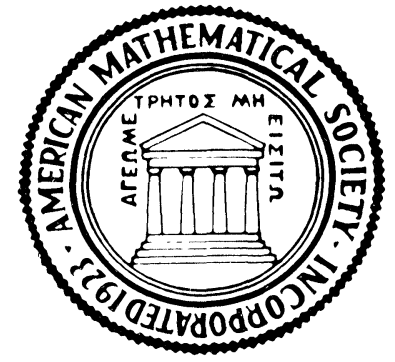

EDITORS

Felix E. Browder, Research-Expository Articles P. R. Halmos, Book Reviews

I. M. Singer, Research Announcements

March 1979

Volume 1, Number 2, Pages 275-442

Providence, Rhode Island USA

ISSN 0002-9904 


\section{BULLETIN (New Series) \\ of the American Mathematical Society}

Volume 1 (1979) of the New Series contains articles of the types listed below. Information on Manuscript, Proof and Copying can be found at the back of this issue of the journal.

\section{RESEARCH-EXPOSITORY PAPERS}

These are by definition papers which present a clear and insightful exposition of significant aspects of contemporary mathematical research. Gibbs lectures and retiring presidential addresses will be included in this section. Manuscripts should be submitted to Professor Felix Browder, Department of Mathematics, University of Chicago, 5734 University Avenue, Chicago, Illinois 60637.

\section{RESEARCH ANNOUNCEMENTS}

The purpose of this department is to provide quick publication of new and significant results of interest to mathematicians. Collectively, the editorial board for research announcements will choose approximately fifteen papers for each issue of the BULLETIN. The deadlines for submission are August 15 for the January issue, October 1 for the March issue, December 1 for the May issue, February 1 for the July issue, April 1 for the September issue and June 1 for the November issue. Announcements are limited to 125 typed lines of 70 spaces each. Authors should send five copies of each manuscript (to speed the decision process) to I. M. Singer, Executive Editor for Research Announcements, Department of Mathematics, Evans Hall, University of California, Berkeley, California 94720. Authors are requested to include an introductory paragraph intelligible to the nonexpert stating the nature and significance of their results. Sketches and/or ideas of proof must be included.

\section{REVIEWS OF BOOKS ON ADVANCED MATHEMATICS}

Book Reviews and any other communication concerning the BULLETIN should be sent to Professor P. R. Halmos, Department of Mathematics, Indiana University, Bloomington, Indiana 47401.

SUBSCRIPTION INFORMATION: THE BULLETIN OF THE AMERICAN MATHEMATICAL SOCIETY is published bimonthly. Subscription prices for Volume 1 (1979) are $\$ 22.00$ list; $\$ 11.00$ member. The subscription price for members is included in the annual dues. Combination paper and microform (microfiche or microfilm) subscription prices are $\$ 30.00$ list; $\$ 15.00$ member. Microfiche of each issue will be mailed the fastest way before the camera copy is sent to the printer.

BACK NUMBER INFORMATION: Back number prices per volume are for Volumes 1-55; $\$ 28.00$ list, $\$ 21.00$ member; for Volumes $56-80$, $\$ 21.00$ list, $\$ 15.75$ member; for Volume 81 , $\$ 27.00$ list, $\$ 20.25$ member; for Volumes $82-84, \$ 36.00$ list, $\$ 27.00$ member. Back volumes are also available on $16 \mathrm{~mm}$ positive or negative microfilm. The microfilm may be mounted on spools or in Kodak or $3 \mathrm{M}$ cartridges. Only current subscribers are eligible to purchase back volumes on microfilm. Write to the Society for a detailed price list. Subscriptions and orders for publications should be addressed to the American Mathematical Society, P.O. Box 1571, Annex Station, Providence, R.I. 02901. All orders must be accompanied by payment. Other correspondence should be addressed to the Society at P.O. Box 6248, Providence, R.I. 02940.

Second class postage paid at Providence, Rhode Island, and additional mailing offices.

U.S. Postal Service Publication No. 075640

Copyright $\odot$ American Mathematical Society 1979

Information on Copying can be found at the back of this journal. 